African Journal for Physical, Health Education,

Recreation and Dance (AJPHERD)

Vol. 12, No. 3 (September) 2006, pp. 287-297.

\section{INFLUENCE OF PREVIOUS \\ PARTICIPATION IN PHYSICAL ACTIVITY ON ITS PERCEPTIONS \\ AMONG TERTIARY INSTITUTION STUDENTS}

\section{D.K. Tumusiime and J.M. Frantz}

\section{ABSTRACT}

Physical inactivity is one of the leading causes of the major non-communicable diseases, which contribute substantially to the global burden of diseases, death and disability. The burden of mortality, morbidity and disability attributable to non-communicable diseases is currently greatest and is continually growing in the developing countries. Most declines in physical activity (PA) occur during the transition period when a person goes from high school to College or University. The objectives of this study were to identify perceived benefits of and barriers to PA and determine whether previous participation in PA does have an influence on these perceptions. A crosssectional and descriptive study with quantitative design was conducted. Five hundred (500) tertiary institution students were randomly sampled from purposively selected departments and classes at each of the five government educational tertiary institutions in Rwanda. A pre-coded self-administered questionnaire with a small number of open-ended questions was administered to the students. A response rate of $425(85 \%)$ was obtained. Descriptive and inferential statistics were used to analyse the data, by means of SAS version 8 software. Frequencies and percentages for mean score values with standard deviations for each perception variable were descriptively obtained. False Discovery Rate (FDR) at $5 \%$ for multiple test adjustment and Spearman's correlation (r) tests were used to identify the significant influence of previous participation on perceptions. More than $70 \%$ students were not participating in PA at tertiary level. Psychological benefits of PA were some of the most important perceived benefits cited by the students. Most of the important barriers cited concerned equipment and time constraints to exercising. Associations were found between previous participation and the current perceptions of PA. The findings of this study demonstrate that previous participation can influence perceptions of PA among the students. Physical activity promotion programmes should consider the role of these factors which should be emphasised from childhood.

Key Words: Physical activity, students, perceived benefits, perceived barriers, previous participation, sedentary lifestyle, Rwanda.
D.K. Tumusiime, MSc. Physiotherapy

Department of Physiotherapy, Kigali

Health Institute, Rwanda

J.M. Frantz, PhD Physiotherapy

Department of Physiotherapy,

University of the Western Cape,

South Africa

\section{E-mail:jfrantz@uwc.ac.za}

\section{INTRODUCTION}

Lack of physical activity or sedentarism, is one of the leading causes of the major noncommunicable diseases, which contributes substantially to the global burden of diseases, death and disability (WHO, 2002). Preliminary data from a World Health Organisation (WHO) study on risk factors suggest that inactivity is one of the ten leading global causes of death and disability. More than two million deaths each year are attributable to physical inactivity (WHO, 2002; WHO, 2003a). According to Booth (2000), chronic diseases of lifestyle accounts for $50 \%$ of all deaths in developing economies and $85 \%$ in developed economies. Physical inactivity is an established risk factor for cardiovascular disease, colon cancer and probably other cancers, non-insulin-dependent diabetes, overweight, hypertension, anxiety and depression (Booth, Bauman \& Owen, 2002).

It is estimated that by 2020 , chronic diseases of lifestyle in sub-Saharan Africa will constitute almost $50 \%$ of the burden of disease (Sobngwi, Mbanya, Unwin, Aspray \& Albert, 2001). Rwanda, as one of the African countries, is faced with similar challenges. 
Following the successful World Health Day (2002) with the theme "Move for Health", the World Health Assembly (WHA) urged Member States to celebrate a "Move for Health" Day each year to promote physical activity as being essential for health and well being. At the $55^{\text {th }}$ WHA, "Move for Health" was launched as part of a broader WHO initiative to address the growing burden of chronic diseases through its Global Strategy on Diet, Physical Activity and Health (WHO, 2003b).

According to a study carried out in Rwanda on "habitual activity patterns among adolescent learners" it was concluded that these learners spent more hours on sedentary activities than non-sedentary activities (Murenzi, 2001). Bray and Born (2004) highlighted that the transition from high school to college or university is a complex phenomenon that has been a topic of sustained interest to both education professionals and researchers. The transition presents a process characterised by change, ambiguity and adjustment across a number of previously salient life domains, which include changes in social, physical activity, psychological, emotional and even cultural in nature. Therefore, physical activity is altered during the transition; it may have important physical and psychological consequences for the university or college students. Sallis et al. (1999) stated that physical activity is influenced by a variety of psychological, social, cultural, and environmental factors. It is reasonable to assume that effective interventions could alter those variables that appear to mediate the behaviour. Modifiable variables have been consistently associated with physical activity. These are self-efficacy, social support, perceived barriers, perceived benefits, and enjoyment (Sallis, et al., 1999).

In Africa, particularly in Rwanda, there is scarcity of information about students' perceived benefits of, barriers and the influence of previous participation in physical activity. This study aimed to determine the perceived benefits of, perceived barriers and the influence of previous participation in physical activity on the perceptions, among tertiary institution students in Rwanda.

\section{METHODOLOGY}

The study was conducted in government tertiary institutions in the Republic of Rwanda. A descriptive quantitative study design was used. The survey was cross-sectional in nature and a self-administered questionnaire was used to collect the data from the students. The study population included all the government tertiary institution students registered for the 2003 academic year in the Republic of Rwanda. 
The total number of this population was approximately 15000 students that were registered for a full-time study programme at the five government tertiary institutions. A sample of five hundred (500) students was selected from this population. The study used two sampling techniques namely purposive and random sampling techniques. The purposive sampling technique was used to select a representative sample from the different departments in each faculty. Random sampling was used to select the appropriate number of students from the purposively selected classes.

\section{Instrumentation}

A structured self-administered questionnaire with both close-ended and a small number of open-ended questions were used. The questionnaire for this study comprised an introductory letter on the first page, which explained the purpose of the study, the request for the respondents to participate and ethical issues considered. The questionnaire was divided into three sections: $\mathrm{A}, \mathrm{B}$ and $\mathrm{C}$. It was designed to assess background characteristics regarding previous physical activity participation, the perceived benefits of, and perceived barriers to physical activity, respectively, among the tertiary institution students in Rwanda.

Section A required the students to tick the appropriate boxes or provide a Yes/No response. Sections B, and C required students to tick an appropriate box, which indicated 4point Likert rating scale responses, $(4=$ strongly agree, 3 = agree, 2 = disagree, $1=$ strongly disagree). After each section (B \& C), open-ended questions were included to obtain additional information from the students. The questionnaire was adapted from the components of Health Belief Model (HBM) and used to assess physical activity perceptions among high school adolescent learners (Tergerson \& King, 2002). The questionnaire was modified by removing and adding some items. The modification was based on another questionnaire, which was developed by $\mathrm{Wu}$ and others to measure physical activity cognitions, mainly perceived benefits and barriers among the youth (Wu et al., 2002). Modification of the adapted questionnaire was done with consideration to the Rwandan environment from which the current study was conducted. A pilot study was done to test the content validity and reliability of the adapted questionnaire among the tertiary institution students in Rwanda, prior to the main study. The correlations from the pilot study were highly significant $(\mathrm{p}<0.005), \mathrm{r}=0.82$ for perceived benefits and $\mathrm{r}=0.87$ for perceived barriers. However, after the pilot study, some questions, which were not clearly understood by the students, were modified and some, which appeared repetitive, were deleted. 
Based on the aim of the study, which was to ascertain the perceived benefits of, and barriers to physical activity among tertiary institution students and to find out whether there was an influence of previous participation in physical activity on the perceptions, both descriptive and inferential statistics analysis were carried out. The SAS version 8 was employed in both analyses.

\section{RESULTS}

From a total of 500 questionnaires that were distributed among tertiary institution students, 425 were completed and returned, giving a response rate of $85 \%$. More than $70 \%$ students were not participating in physical activity at tertiary level.

\section{Perceived benefits of physical activity}

Regarding the question on perceived benefits, the students were asked to respond according to the questions on the reasons why they exercise or would consider exercising. Table 1 illustrates that the five most likely benefits of physical activity considered by the respondents to be the reasons for exercise were "Exercise helps me to reduce stress" (with the mean score $\mathrm{M}=3.277)$, "Exercise improves my self-esteem (feel better about my self)" ( $(\mathrm{M}=3.234)$, "Exercise helps me to increase my energy level", $(\mathrm{M}=3.212)$, "Exercise helps me to become strong" $(\mathrm{M}=3.209)$, and "Exercise improves my Cardiovascular Fitness (protects my heart)"' $(\mathrm{M}=3.200)$. The least likely benefits of physical activity considered by the students were "Exercise helps me to lose weight", $(\mathrm{M}=2.562)$, and "Exercise helps me to become more physically attractive to others" $(M=2.752)$.

\section{Perceived barriers to physical activity}

As shown in Table 2 below, the three most likely barriers to physical activity perceived by the students were "I do not have right equipment to exercise" $(\mathrm{M}=2.616)$, "I want to do other things with my time" (M=2.563), and "There are other interesting things to do" $(\mathrm{M}=2.550)$. The least likely barriers to physical activity considered by the students were " $I$ do not think exercise is important" $(\mathrm{M}=1.856)$, and "I am not interested in exercising" $(\mathrm{M}=1.925)$.

\section{Influence of previous participation in physical activity on current perceptions of physical activity}

In view of the fact that doing the analysis of this variable was to look at many tests, it was important to include an adjustment for multiple testing in the tests done. The Bonferroni adjustment is commonly used for this purpose, but it is too conservative. Therefore, the False Discovery Rate (FDR) which is less conservative (Stokes et al., 1995) was also included. 
Table 1: Perceived benefits of physical activity

\begin{tabular}{|c|c|c|c|c|c|c|}
\hline Variable statements & $\mathrm{N}$ & Mean score & $\begin{array}{l}\text { Strongly agree } \\
(\%)\end{array}$ & $\begin{array}{l}\text { Agree } \\
(\%)\end{array}$ & $\begin{array}{l}\text { Disagree } \\
(\%)\end{array}$ & $\begin{array}{l}\text { Strongly } \\
\text { disagree (\%) }\end{array}$ \\
\hline Exercise helps me to reduce stress & 412 & 3.277 & 39.1 & 50.2 & 10.0 & 0.7 \\
\hline $\begin{array}{l}\text { Exercise improves my self-esteem (feel better } \\
\text { about my self) }\end{array}$ & 418 & 3.234 & 32.3 & 59.6 & 7.4 & 0.7 \\
\hline Exercise helps me to increase my energy level & 420 & 3.212 & 32.6 & 58.1 & 7.1 & 2.1 \\
\hline Exercise helps me to become strong & 422 & 3.209 & 31.1 & 59.3 & 7.5 & 1.4 \\
\hline $\begin{array}{l}\text { Exercise improves my cardiovascular fitness } \\
\text { (protects my heart) }\end{array}$ & 416 & 3.200 & 31.7 & 58.9 & 7.0 & 2.4 \\
\hline Exercise allows me contact with my friends & 417 & 3.192 & 35.5 & 51.6 & 9.6 & 3.4 \\
\hline Exercise helps me to stay in shape & 421 & 3.147 & 31.8 & 53.6 & 10.1 & 3.5 \\
\hline I have fun when I exercise & 412 & 2.980 & 27.4 & 48.3 & 9.4 & 4.9 \\
\hline $\begin{array}{l}\text { Exercise helps me to be competitive (enjoy } \\
\text { competition with others) }\end{array}$ & 420 & 2.952 & 24.3 & 50.7 & 21 & 4 \\
\hline $\begin{array}{l}\text { Exercise helps me to do something attractive } \\
\text { with other people }\end{array}$ & 409 & 2.858 & 19.6 & 52.1 & 23 & 5.4 \\
\hline $\begin{array}{l}\text { Exercise helps me to become more physically } \\
\text { attractive to others }\end{array}$ & 408 & 2.752 & 18.4 & 43.9 & 32.4 & 5.4 \\
\hline Exercise helps me to lose weight & 413 & 2.562 & 12.1 & 43.1 & 33.7 & 11.1 \\
\hline Average & 416 & 3.048 & 27.99 & 52.45 & 15.68 & 3.75 \\
\hline
\end{tabular}

Table 2: Perceived barriers to physical activity

\begin{tabular}{|c|c|c|c|c|c|c|}
\hline Variable statements & $\mathrm{N}$ & Mean score & $\begin{array}{l}\text { Strongly } \\
\text { agree }(\%)\end{array}$ & $\begin{array}{l}\text { Agree } \\
(\%)\end{array}$ & $\begin{array}{l}\text { Disagree } \\
(\%)\end{array}$ & $\begin{array}{c}\text { Strongly } \\
\text { disagree }(\%)\end{array}$ \\
\hline I do not have right equipment to exercise & 417 & 2.616 & 17.3 & 38.6 & 32.6 & 11.5 \\
\hline I want to do other things with my time & 419 & 2.563 & 12.4 & 42.2 & 34.6 & 10.7 \\
\hline There are other interesting things to do & 416 & 2.550 & 11.8 & 41.1 & 37.5 & 9.6 \\
\hline I have too much home work & 415 & 2.429 & 9.2 & 37.6 & 40.2 & 13 \\
\hline I do not have time to exercise & 415 & 2.376 & 11.8 & 28 & 46.3 & 14 \\
\hline $\begin{array}{l}\text { I do not have a good place to go and } \\
\text { exercise }\end{array}$ & 417 & 2.350 & 10.8 & 27.3 & 48.0 & 10.8 \\
\hline I am not motivated & 414 & 2.256 & 7.2 & 29.2 & 45.4 & 18.1 \\
\hline Exercise tires me & 414 & 2.193 & 5.3 & 26.8 & 49.8 & 18.1 \\
\hline $\begin{array}{l}\text { I do not have safe a environment to go and } \\
\text { exercise }\end{array}$ & 413 & 2.179 & 9.2 & 19.9 & 50.6 & 20.3 \\
\hline I do not have any one to exercise with & 413 & 2.102 & 6.3 & 21.5 & 48.2 & 24.0 \\
\hline $\begin{array}{l}\text { I do not think exercise will give the results } \\
\text { that I want }\end{array}$ & 416 & 2.099 & 6.0 & 20.4 & 51.0 & 22.6 \\
\hline I think exercise is too hard & 413 & 2.083 & 5.8 & 16.9 & 6.9 & 20.3 \\
\hline I do not enjoy exercising & 415 & 1.990 & 4.3 & 18.3 & 49.4 & 28.0 \\
\hline I do not know how to exercise & 417 & 1.964 & 7.9 & 9.4 & 54.0 & 28.8 \\
\hline I am not interested in exercising & 416 & 1.925 & 7.0 & 10.8 & 50.0 & 32.2 \\
\hline I do not think exercise is important & 416 & 1.856 & 7.2 & 6.5 & 1.0 & 35.3 \\
\hline Average & 415 & 2.24 & 8.7 & 24.65 & 46.6 & 19.8 \\
\hline
\end{tabular}


With (FDR) $\mathrm{p}<0.05$, associations between previous participation in physical activity and current perceptions on physical activity were determined. It was discovered that the section of perceptions with the most associations with previous participation, is perceived barriers (Table 3).

The Spearman's correlation test was used to determine whether the associations found (as presented in Table 3) between previous participation in physical activity and perceptions, were positive or negative associations. It was noted that in most of the cases where the associations were significant, the correlations were negative, as presented in Figures 1 and 2 for perceived benefits and perceived barriers, respectively. The perceived benefits of physical activity namely, "exercises help me to become more physically attractive to others" (5 in Figure 1) and "exercise helps me to do something attractive with other people" (6 in Figure 1), which were significant $(\mathrm{r}$ - values on page 10) are all towards the left, meaning they were negatively correlated to the previous participation in physical activity for current perceptions on physical activity. This indicates that the students who previously participated in physical activity, strongly disagreed that each of the two perceived benefits of physical activity is an important reason for them to currently participate in physical activity, while benefits like "exercise improves my cardiovascular fitness" (No. 7) and "exercise reduces stress" (No. 9) were the two most positively correlated perceptions to previous participation in physical activity. This indicates that the students, who previously participated highly in physical activity, strongly agreed that each of the two perceived benefits of physical activity is an important reason for them to currently participate in physical activity.

Figure 2 indicates the students, who previously participated in physical activity strongly disagreed that most of the perceived barriers to physical activity are important reasons stopping them from participating in physical activity.

Perceived benefits and their values (r) of significance

1. Exercise helps me to stay in shape $(r=$ 0.93483 )

2. Exercise helps me to become strong $(\mathrm{r}=$ 0.82160 )

3. Exercise helps me to be competitive $(r=$ 0.05472 )

4. Exercise helps me to increase my energy level ( $\mathrm{r}$ $=0.51330$ )

5. Exercise helps me to become more physically attractive to others $(\mathrm{r}=0.00564 *)$

6. Exercise helps me to do something attractive with others $(\mathrm{r}=0.03383 *)$

7. Exercise improves my cardiovascular fitness $(\mathrm{r}=$ $0.32652)$

8. Exercise improves my self-esteem $(\mathrm{r}=0.36149)$

9. Exercise reduces stress $(\mathrm{r}=0.57839)$

10. Exercise helps me to have fun $(\mathrm{r}=0.73458)$

11. Exercise helps me to reduce weight $(\mathrm{r}=0$. 0.93483 )

12. Exercise helps me to have contact with my friends $(\mathrm{r}=0.51330)$

* = statistically significant correlation 
Table 3: Significantly associated perceptions with previous participation in physical activity

\begin{tabular}{|c|c|c|}
\hline Perceived benefits: & FDR_P-value & Level of significance \\
\hline Exercise helps me to stay in shape & 0.93483 & NS \\
\hline Exercise helps me to become strong & 0.82160 & NS \\
\hline Exercise helps me to be competitive & 0.05472 & NS \\
\hline Exercise helps me to increase my energy level & 0.51330 & NS \\
\hline Exercise helps me to become more physically attractive to others & $0.00564 *$ & $\mathrm{~S}$ \\
\hline Exercise helps me to do something attractive with others & $0.03383 *$ & S \\
\hline Exercise improves my cardiovascular fitness & 0.32652 & NS \\
\hline Exercise improves my self-esteem & 0.36149 & NS \\
\hline Exercise reduces stress & 0.57839 & NS \\
\hline Exercise helps me to have fun & 0.73458 & NS \\
\hline Exercise helps me to reduce weight & 0.93483 & NS \\
\hline Exercise helps me to have contact with my friends & 0.51330 & NS \\
\hline \multicolumn{3}{|l|}{ Perceived barriers: } \\
\hline I do not have time to exercise & $0.01194 *$ & S \\
\hline I want to do other things with my time & 0.09363 & NS \\
\hline I do not have good places to go and exercise & 0.09076 & NS \\
\hline I do not know how to exercise & $0.00000 *$ & $S$ \\
\hline I do not have a safe environment to go and exercise & $0.00019 *$ & S \\
\hline I do not have right equipment to exercise & $0.02960 *$ & $S$ \\
\hline I do not think exercise will give the results that I want & $0.00799 *$ & $\mathrm{~S}$ \\
\hline Exercise tires me & 0.24648 & NS \\
\hline I am not motivated to exercise & 0.05472 & NS \\
\hline I do not enjoy exercising & 0.07051 & NS \\
\hline I am not interested in exercising & $0.02773^{*}$ & $S$ \\
\hline I think that exercise is too hard & $0.01293 *$ & $S$ \\
\hline I do not think exercise is important & $0.00030 *$ & S \\
\hline I do not have any one to exercise with & $0.00039 *$ & $\mathrm{~S}$ \\
\hline There are other interesting things to do & 0.30344 & NS \\
\hline I have too much home work to do & 0.09076 & NS \\
\hline
\end{tabular}

* Denotes statistic significant FDR value at significance level of $0.05 . \mathrm{S}=$ Significant; NS = Not significant

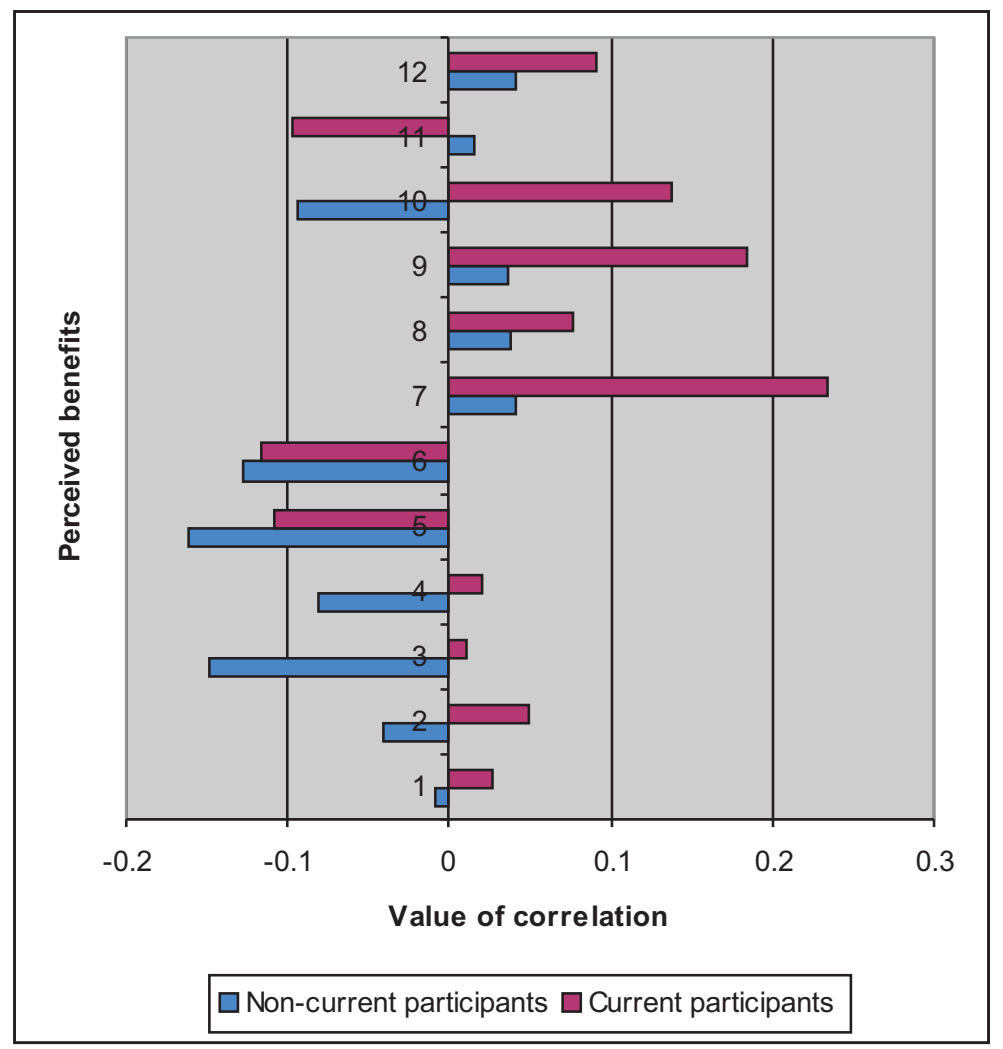

Figure 1: Correlation between previous participation and perceived benefits of physical activity 


\section{DISCUSSION}

This study aimed to ascertain perceptions of physical activity, specifically; perceived benefits and perceived barriers to physical activity, and also to explore whether there is an influence of previous participation in physical activity on the current perceptions, among tertiary institution students in Rwanda. Theoretical models help to explain how physical activity behaviours can be influenced. From these theories, strategies can be derived to facilitate the adoption of more active lifestyles, such as helping people to find more benefits than barriers (Nahas, Goldfine \& Mitchell., 2003). However, it is strategically important to first identify what the people know before helping them to find what they do not know.

This study found that more than $70 \%$ were not participating in physical activity at tertiary level. Bray \& Born (2004) demonstrated with their study that participation in physical activity usually decreases tremendously during the transition from the secondary to tertiary levels of education. This indicates a serious need for physical activity promotion at tertiary education level, especially in Rwanda. Students in Rwanda considered psychological, physical and physiological benefits of physical activity to be very important. Reducing stress and improvement of self-esteem were the most important psychological benefits while increasing energy, strength and improvement of cardiovascular fitness were the important physical and psychological benefits of physical activity cited in this study. Biddle and Mutrie (2001) had also highlighted reducing stress and improvement of self-esteem as some of the important psychological benefits of physical activity. Scientific literature shows that the significant physical and psychological benefits of physical activity for individuals should be attended to during the intervention programmes (Juarbe et al., 2002). Therefore, the important benefits, cited by the students in this current study can be given attention during health education programmes to promote physical activity among the tertiary institution students in Rwanda. Nevertheless, some benefits of physical activity were cited to be more important than others in this study, but in general, the students perceived most of the benefits of physical activity to be important reasons to exercise or even considering exercising. This makes it interesting and important for physical activity promoters in Rwanda to use benefits of physical activity to encourage and motivate the population specifically the students for physical activity participation in future interventions. 
Regarding perceived barriers, students in the current study emphasised lack of equipment and time as well as having interest in doing other things to be the most important barriers. Nahas et al. (2003) mentioned that in most of the studies, the principle reason for people not being active is lack of time. However, the same authors contend that "lack of time" may also fall under the category of "convenient excuses" for not being physically active. Therefore, identifying the reasons for the lack of time among the Rwandan tertiary institution students is important for further research and intervention purposes because different students may have different reasons for lack of time. However, it seems students in Rwanda have some slight differences regarding barriers to physical activity, from what is reported in the literature by other studies from different research settings. It may seem that in a country like Rwanda that is recovering from major civil war, other public health concerns are considered to be more important than physical activity participation. However, it is high time that health promoters in Rwanda emphasise participation in physical activity. Lack of physical activity which is becoming another major public health concern, was highly recommended by WHO (WHO, 2002) and even more emphasised at the recent $57^{\text {th }}$ WHA (WHA, 2004). It is encouraging that most of the students in this study disagreed (46.4\%) and $19.8 \%$ strongly disagreed that barriers are not important reasons to stop them from participating. However, $24.65 \%$ agreed that barriers are important reasons to stop them from participating in physical activity. This group of students needs to be focused on and be helped to overcome the barriers to physical activity participation. Associations were found between previous participation and the current perceptions on physical activity. Most negative associations were found with the perceived barriers. Students that previously participated are not likely to perceive many barriers to participation. According to Sumnisk et al. (2002) early or previous (childhood, adolescence) participation in physical activity is likely to be carried over into adulthood. This suggests that physical activity promotion programmes should consider the factors influencing the physical activity perceptions during the interventions, and the programmes should be emphasized right from childhood.

\section{CONCLUSION}

The findings of this study indicate that more than $70 \%$ were not actively participating in physical activity at tertiary level. However, these tertiary institution students considered that benefits of physical activity were important reasons for participation in physical activity and the majority included psychological benefits. 
Most of the barriers to participation were lack of equipment and time constraints. The study also found that there was an influence of previous participation on current perceptions of physical activity among the tertiary institution students.

\section{RECOMMENDATIONS}

1. It is recommended that physical-activity promotion intervention be incorporated into the tertiary education institutions' programmes, as health education. Particular health education should focus on information that would reflect physical activity as not to be time consuming in order to elimate some of the greatest perceived barriers.

2. It is important that the institutions' physical activity promotion programmes should use the students' most strongly perceived benefits of physical activity such as psychological wellbeing and physiological benefits of physical activity. These should be focused on as motivational factors to participation in physical activity.

3. Strategies to promote lifelong physical activities in physical should be emphasized and health education programmes should be designed, thus helping to establish an early pattern of physical activity behaviour that can persist into the adult years

\section{REFERENCES}

Biddle, S.J. H. \& Mutrie, N. (2001). Psychology of Physical Activity. London: Routledge.
Booth, M. (2000). Assessment of physical activity: An international perspective. Research Quarterly for Exercise and Sport, 71, 114-120.

Booth, M.L., Bauman, A., \& Owen, N. (2002). Perceived barriers to physical activity among older Australians. Journal of Aging and Physical Activity, 10(3), 11pgs.

Bray, R. S. \& Born, A.H. (2004). Transition to University and Vigorous Physical Activity: Implications for Health and Psychological Well-Being. Journal of American College Health, 52, 181-187.

Juarbe, T., Turok, X., Perez-Stable, E. (2002). Perceived benefits and barriers to physical activity among older Latina women. Western Journal of Nursing Research, $24,868-886$.

Murenzi, J.G. (2001). Habitual Activity patterns among adolescent learners in Rwanda. Unpublished Master of Science thesis. Physiotherapy department, University of the Western Cape.

Nahas, M.V., Goldfine, B. \& Mitchell, A. (2003). Determinants of physical activity in adolescents and young adults: the basis for school and college physical education to promote active lifestyle. Physical Educator, $60,42-57$.

Sallis, J.F., Calfas, K.J., Nichols, J.F., Sarkin, A.J., Marilyn, F.J., Caparosa, S., Thompson, S. \& Alcaraz, E.J. (1999). Evaluation of a University Course to Promote Physical Activity: Project GRAD. Research Quarterly for Exercise and Sport, 70, 1-10.

Sobngwi, E., Mbanya, J.C.N., Unwin, N.C., Aspray, T.J. \& Albert, K.G.M.M. (2001). Development and validation and questionnaire for assessment of physical activity in epidemiological studies in Sub-Saharan African. International Epidemiological Association, 30, 1361-1368.

Sumnisk, R.R., Petosa, R., Utter, A.C. \& Zhang, J.J. (2002). Physical activity among ethically diverse college students. Journal of American College Health, 51, 7580.

Tergerson, J.L. \& King, K.A. (2002). Do cues, benefits, and barriers to physical activity differ between male and female adolescents? Journal of School Health, 72, 374381 . 
World Health Assembly (2004). Global strategy on diet, physical activity and health. Fifty-seventh World Health Assembly, [Online] Available: http:// www.who.int+57th+WHA [30/10/2004].

World Health Organisation (2002). Physical Activity and Youth: "Move for Health": World Health Day 2002. [Online]: Available. http://www.who.int/archives/worldhealth-day/fact sheets2.en.shtml. [14/4/03].

World Health Organisation (2003a). Sedentary lifestyle: a global public health problem. Physical activity, Noncommunicable disease prevention and health promotion. [Online]:Available.

http://www.who.int/hpr/physactiv/sedentary.lifestylel.sht ml [24/4/03].

World Health Organisation (2003b). WHO launches annual Move for Health day as global initiative to promote benefits of physical activity: Media centre. [Online]:Available.

http://www.who.int/mediacentre/release/2003/prl5/en/.

[24/4/03].

Wu, T.Y., Ronis, D.L., Pender, N., Faan, R.N. \& Jwo, J. (2002). Development of Questionnaires to measure physical activity cognitions among Taiwanese adolescents. Preventative Medicine, 35, 54-64. 